\title{
Mitochondrial DNA Variation of Triatoma infestans Populations and its Implication on the Specific Status of T. melanosoma
}

\author{
Fernando A Monteiro/*/+, Ruben Pérez**, Francisco Panzera**, Jean-Pierre \\ Dujardin***, Cleber Galvão****, Dayse Rocha****, Francois Noireau****, \\ Chris Schofield*****, Charles B Beard
}

Centers for Disease Control and Prevention, 4770 Buford Hwy MS: F-22, 30341-3724 Atlanta, USA *Depto de Genetica, Universidade Federal do Rio de Janeiro, Rio de Janeiro, Brazil **Sección Genética Evolutiva, Facultad de Ciencias, Montevideo, Uruguay ***Institut de Recherche pour le Development, La Paz, Bolivia

****Laboratório Nacional e Internacional de Referência em Taxonomia de Triatomíneos, Departamento de Entomologia, Instituto Oswaldo Cruz, Rio de Janeiro, RJ, Brasil *****London School of Hygiene and Tropical Medicine, London, UK

DNA sequence comparison of 412 base-pairs fragments of the mitochondrial cytochrome $B$ gene was used to infer the genetic structure of nine geographical Triatoma infestans populations and their phylogenetic relationship with T. melanosoma and T. brasiliensis. T. infestans and T. melanosoma were compared by morphometry, allozyme and cytogenetic analyses, as well as subjected to reciprocal crosses, in order to clarify the taxonomic status of the latter. No differences were found to distinguish the two species and the crosses between them yielded progeny.

T. infestans populations presented four haplotypes that could be separated in two clusters: one formed by the samples from Bolivia (Andes and Chaco) and the other formed by samples from Argentina and Brazil. Silvatic and domestic T. infestans populations from Bolivia (Andes) were genetically identical.

Key words: Triatoma infestans - Triatoma melanosoma - mitochondrial DNA - cytogenetics - allozymes phylogeny - molecular systematics - Chagas disease vectors

Triatoma infestans is the most widespread domestic vector of Chagas disease (American trypanosomiasis) in South America. As a consequence it has also been the main target of the Southern Cone Initiative, a triatomine vector control campaign that relies largely on residual insecticides to eradicate domestic and peri-domestic insect populations from infested areas. The success of this control campaign is based on the fact that true natural silvatic $T$. infestans colonies are very rare and found exclusively in the Cochabamba Valley in Bolivia (Dujardin et al. 1987), therefore largely precluding the recolonization of treated areas by insects coming from silvatic foci.

This work benefited from the ECLAT network.

The use of trade names does not constitute endorsement by the U.S. Public Health Service or the Centers for Disease Control and Prevention.

${ }^{+}$Corresponding author sponsored by Capes, Brasília, Brazil. Fax: +770-488-4258. E-mail: fdm8@cdc.gov

Received 9 June 1999

Accepted 9 August 1999
Moreover, it has been sugested that as a consequence of the recent adaptation of some T. infestans populations to human dwellings, a process of isolation between silvatic and domestic populations could be underway. Although silvatic and domestic T. infestans populations from Bolivia are virtually identical based on allozyme markers (Dujardin et al. 1987), morphometric differences between them have been interpreted as an indication of incipient separation (Dujardin et al. 1997). The trend of silvatic T. infestans populations living in rockpiles (associated with guinea-pigs) towards domesticity (and association with humans) is the first step in Schofield's (1988) historical reconstruction hypothesis to explain the current distribution of the species.

In this paper we use mitochondrial DNA sequence variation to compare sylvatic and domestic T. infestans populations from Cochabamba, Bolivia, to see if the differences detected by the morphometric analysis (and not by allozymes) are revealed by the use of a method that has proved to be more sensitive in addressing problems in systematics (Lyman et al. 1999). These two populations are added to a broader comparison that in- 
cludes insects from other Bolivian populations and also populations from Argentina and Brazil. The aim of this geographical analysis was to try to detect any evidence of substructuring of the entire $T$. infestans distribution and to discuss the data in light of current biogeographical hypotheses.

One of the T. infestans samples from Bolivia consisted of recently reported silvatic melanic insects collected from parrot nests in the Bolivian Chaco. This observation prompted the suggestion that this population could belong to the closely related T. melanosoma (Noireau et al. 1997), a totally black triatomine from Misiones, Argentina, and species chosen to be the outgroup in our phylogenetic analysis. The mitochondrial DNA sequence analysis revealed not only an unusually high level of similarity between T. melanosoma and the melanic $T$. infestans, but also between these and all other $T$. infestans populations. Thus we decide to undertake a more comprehensive analysis of these two closely related species employing other morphologic and molecular (cytogenetics and allozymes) methods that have also been successfully used to investigate taxonomic questions in the Triatominae (e.g. Panzera et al. 1995, Dujardin et al. 1997, Noireau et al. 1998). Additionally, to further clarify their status, in terms of genetic compatibility, T. melanosoma and T. infestans were submitted to cross-mating experiments.

\section{MATERIALS AND METHODS}

Triatomine specimens - DNA sequence analysis of 412 base-pares fragments of the mitochondrial Cytochrome B gene (mtCytB) was performed on specimens from nine South American $T$. infestans populations, and on the closely related $T$. melanosoma (Fig. 1). Another species of the " $T$. infestans complex", T. brasiliensis, was used as the outgroup (Table I). The amplified fragments correspond to the region between nucleotides 10851 and 11262 in the Anopheles gambiae mitochondrial genome (Beard et al. 1993).

DNA processing - DNA from individual insect specimens was isolated, purified and amplified according to Lyman et al. (1999).

Primers used for PCR amplification and direct DNA sequencing

Forward: $\quad$ CYT BF

5'- GGA CAA ATA TCA TGA GGA GCA ACA G Reverse: $\quad$ CYT BR

5'-ATT ACT CCT CCT AGC TTA TTA GGA ATT G

Sequence analysis - Amplified PCR fragments were sequenced using flourescent sequencing with dye terminator chemistry (Big dyes ${ }^{\mathrm{TM}}$, Perkin Elmer Applied Biosystems, Foster City, CA) and analyzed on a ABI 377 automated sequencer. Both

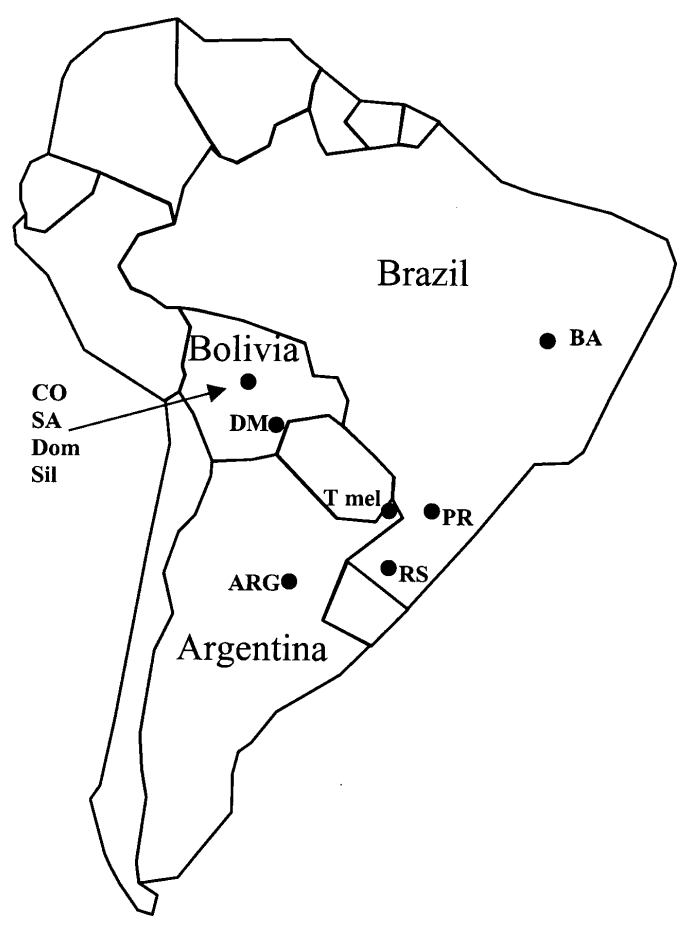

Fig. 1: geographic origin of Triatoma infestans and $T$. melanosoma samples used in the DNA sequence analysis. BA $=$ Bahia, Brazil $; \mathrm{PR}=$ Paraná, Brazil $; \mathrm{RS}=\mathrm{Rio}$ G. do Sul, Brazil; ARG = Santa Fe, Argentina; $\mathrm{CO}=$ Cochabamba, Bolivia; SA = Santivanez, Bolivia; Dom = Jumach'Uma, Bolivia (domestic); Sil = Jumach'Uma, Bolivia (silvatic); DM = Izozog, Bolivia (dark morph); and $\mathrm{T}$ mel $=$ T. melanosoma, Missiones, Argentina.

Observation: Jumach'Uma (Sil) and (Dom) are $1 \mathrm{~km}$ apart. Santivanez and Cochabamba are respectively 5 and $30 \mathrm{~km}$ north from Jumach'Uma.

forward and reverse strands were examined and the resulting DNA sequences analyzed using Sequence Navigator V 1.0.1.(Perkin Elmer Applied Biosystems, Foster City, CA), producing a consensus sequence for each DNA sample used. Sequences were then aligned using Pileup (Wisconsin Package Version 9.1, Genetics Computer Group, Madison, WI, 1997). Phylogenetic analysis was performed by Neighbor Joining (NJ, Saitou \& Nei 1987) and Parsimony methods. NJ (from the MEGA package, Kumar et al. 1993) was used with Tamura and Nei (1993) distances because this model corrects for unequal base composition and also for transition/transversion biases. The robustness of the generated tree was assessed by the bootstrap method (Efron 1982) with 1000 replications. Parsimony analysis was done using the polarized informative characters (Hennig 1966). These were selected from a matrix (not shown) where a comparison with the outgroup was made. The nucleotide position was considered as the character and 
TABLE I

Triatomine bugs used for mitochondrial DNA sequencing

\begin{tabular}{llllc}
\hline Species & Origin & Colony/Field & Habitat & $\begin{array}{c}\text { No. of individuals } \\
\text { analyzed }\end{array}$ \\
\hline Triatoma infestans & Bahia, Brazil & Field & Domestic & 6 \\
& Paraná, Brazil & Field & Domestic & 2 \\
& Rio G do Sul, Brazil & Field & Domestic & 5 \\
& Rio G do Sul, Brazil & Colony & Domestic & 1 \\
& Santa Fe, Argentina & Colony & Domestic & 1 \\
& Jamach'Uma, Bolivia & Field & Domestic & 6 \\
& Jamach' Uma, Bolivia & Field & Silvatic & 6 \\
& Santivanez, Bolivia & Field & Domestic & 1 \\
& Cochabamba, Bolivia & Field & Domestic & 1 \\
T. melanosoma & Izozog, Bolivia & Field & Silvatic & 4 \\
T. brasiliensis & Misiones, Argentina & Colony & Silvatic & 2 \\
\hline
\end{tabular}

the nucleotides as character states. Synapomorphies (shared derived characters) were used to determine the clades that formed the tree. Characters on terminal branches are autapo-morphies (characters that are unique to a terminal lineage). Since the trees built based on both methods (NJ and Parsimony) gave the same topology, only the $\mathrm{NJ}$ tree is shown, with the parsimony characters added to it.

Allozymes - Twenty-four T. melanosoma from Misiones, Argentina (Fiocruz insectary) were compared with eight field collected $T$. infestans from Cochabamba, Bolivia and eight from Presidente Hayes, Paraguay.

Electrophoretic techniques and enzymes were those used in Dujardin et al. (1998).

Cytogenetics - Seven males and one female of T. melanosoma from a laboratory strain founded in 1984 with individuals captured in Misiones (Argentina) were analyzed. We also studied two male hybrids obtained by crossing $T$. infestans (male) with T. melanosoma (female).

Chromosome preparation and banding procedures - Gonads (testes and ovaries) were fixed in ethanol-acetic acid (3:1) and softened in a $45 \%$ aqueous solution of acetic acid. Conventional staining (lacto-acetic orcein) and C-banding techniques (according with Pérez et al. 1992) were applied to squash preparations.

Cytogenetic analysis - Several cytogenetic markers previously used to differentiate triatomine species (Pérez et al. 1992) were analyzed in order to characterize this species. To evaluate the amount of heterochromatin we used the relative length of the autosomal C-heterochromatin in the total length of the autosomal complement. At least two metaphase plates for each one of the C-karyotypes described were analyzed using specific software
(Image Pro-Plus, Media Cybernetics, GA).

In the hybrids, we observed the chromosome behavior in meiosis, paying special attention to the pairing of both sets of homologous chromosomes during metaphases I and II.

Morphometric measurements and analysis The wings of 25 T. melanosoma (from Fiocruz insectary), and 62 domestic T. infestans from Presidente Hayes, Paraguay, were analyzed following standard procedures (Dujardin et al. 1997). Since dispersion matrices showed significant heteroscedasticity and no common principal component model was acceptable (NTSYS 2.02i, detailed analyses not shown), a double centered data was used as input for discriminant analysis.

The results were compared to other published measurements of 19 silvatic and 24 domestic $T$. infestans from Cochabamba (Dujardin et al. 1997).

Cross-mating experiments - Reciprocal crosses among pairwise combinations of T. melanosoma and T. infestans were carried out in order to evaluate the reproductive compatibility of these two species (Table II A and B). Virgin adults were obtained by raising individual fifth instar nymphs in isolation. All species pairs were kept under the same experimental conditions (at room temprature and fed on pigeons, Columbia livia).

\section{RESULTS}

Domestic and silvatic T. infestans - All 12 domestic and silvatic samples of $T$. infestans from Jumach'Uma, Bolivia yielded completely identical nucleotide DNA sequences. This same haplotype was also obtained from the geographically close Santivanez and Cochabamba specimens (Figs 1, 2).

T. infestans geographical variation - The $T$. infestans populations could be separated into four 


\section{TABLE II A}

Results of cross-mating experiments between Triatoma infestans females and T. melanosoma males

\begin{tabular}{|c|c|c|c|c|c|}
\hline Pair & $\begin{array}{l}\text { Number } \\
\text { of eggs }\end{array}$ & $\begin{array}{l}\text { Eggs } \\
\text { hatched }\end{array}$ & $\begin{array}{c}\text { Adults with } T \text {. infestans } \\
\text { phenotype }\end{array}$ & $\begin{array}{l}\text { Adults with } \\
\text { T. melanosoma } \\
\text { phenotype }\end{array}$ & $\begin{array}{c}\text { Adults with } \\
\text { intermediate } \\
\text { phenotype }\end{array}$ \\
\hline 1 & 222 & 151 & 14 females, 16 males & 1 female & - \\
\hline 2 & 237 & 152 & 26 females, 11 males & 1 female & - \\
\hline 3 & 94 & 0 & - & - & - \\
\hline 4 & 31 & 23 & 2 females, 3 males & - & - \\
\hline 5 & 4 & 0 & - & - & - \\
\hline 6 & 33 & 24 & 8 females, 7 males & - & - \\
\hline 7 & 62 & 35 & 5 females, 8 males & - & - \\
\hline 8 & 0 & 0 & - & - & \\
\hline 9 & 221 & 201 & 27 females, 14 males & 1 male & 1 female \\
\hline 10 & 12 & 5 & 2 females, 1 male & - & - \\
\hline 11 & 0 & 0 & - & - & - \\
\hline 12 & 95 & 88 & 8 females, 8 males & - & - \\
\hline 13 & 8 & 0 & - & - & - \\
\hline 14 & 47 & 24 & 7 females, 2 males & - & - \\
\hline 15 & 103 & 86 & 25 females, 24 males & - & 1 female \\
\hline
\end{tabular}

\section{TABLE II B}

Results of cross-mating experiments between Triatoma infestans males and T. melanosoma females

\begin{tabular}{lccccc}
\hline Pair & $\begin{array}{c}\text { Number } \\
\text { of eggs }\end{array}$ & $\begin{array}{c}\text { Eggs } \\
\text { hatched }\end{array}$ & $\begin{array}{c}\text { Adults with T. infestans } \\
\text { phenotype }\end{array}$ & $\begin{array}{c}\text { Adults with } \\
\text { T. melanosoma } \\
\text { phenotype }\end{array}$ & $\begin{array}{c}\text { Adults with } \\
\text { intermediate } \\
\text { phenotype }\end{array}$ \\
\hline 1 & 22 & 0 & - & - & - \\
2 & 220 & 112 & 17 females, 13 males & - & 1 male \\
3 & 26 & 14 & 7 females, 4 males & - & - \\
4 & 118 & 65 & 9 females, 12 males & - & - \\
5 & 78 & 17 & 1 female, 3 males & - & - \\
6 & 0 & 0 & - & - & - \\
7 & 66 & 34 & 5 females, 1 male & - & - \\
8 & 189 & 123 & 15 females, 10 males & - & - \\
9 & 45 & 39 & 24 females, 8 males & - & - \\
10 & 119 & 81 & 15 females, 14 males & - & - \\
11 & 97 & 37 & 8 females, 10 males & - & - \\
12 & 11 & 0 & - & - & - \\
\hline
\end{tabular}

nucteotide position

$\begin{array}{llllll}11111 & 1111111111 & 1122222222 & 2222233333 & 33333344\end{array}$

$\begin{array}{llllllll}12334556 & 6788912333 & 4555666888 & 8833345778 & 8899901123 & 34568900\end{array}$ $3924698570 \quad 35789103891067238023 \quad 6916739192 \quad 6814792513 \quad 69434325$

T. brasiliensis

T. infestans (BRA-BA)

T. infestans (BRA-RS)

T. infestans (ARG)

T. melanosoma

T. infestans (BRA-PR)

T. infestans (BOL-Sil)

T. infestans (BOL-Dom)

T. infestans (BOL-SA)

T. infestans (BOL-CO)

T. infestans (BOL-DM)

Consensus

nt position in codon 3333333133333133313133313133233332331133133333333331333333

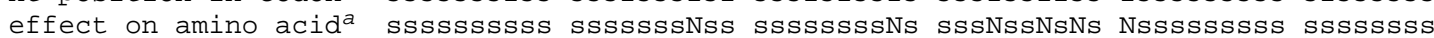

Fig. 2: alignment of variable nucleotide positions of mtCytb sequences (412 bp) for all populations/species; $a$ : nt substitutions are synonymous (s) or are non-synonymous (N), and yield to an amino acid change. 
distinct haplotypes without any intra-populational variation detected. A very clear differentiation was found between the Bolivian samples and the other samples from Brazil and Argentina. The Bolivian samples presented two different haplotypes, one for the Andean populations and the other for the Chaco (melanic) population. This clade (Bolivian samples) was well supported by two synapomorphies (nt positions 288 and 384) and by a bootstrap value of 72 in the NJ analysis (Fig. 3). Insects from Argentina and Brazil share one most common haplotype with a slightly different one showed by the Brazilian Paraná (PR) sample (and T. melanosoma, see below). The clade they formed was supported by one synapomorphy (nt position 186 ) and by a bootstrap value of 86 (Fig. 3). Fifty characters supported the T. infestans/T. melanosoma clade and the six remaining variable characters were exclusive to the terminal branches $(63$, 183, 243, 297 and 354). There were no conflicting (homoplastic) characters in the parsimony analysis. The four haplotypes were determined by eight variable nucleotide (nt) sites. All eight variable sites were third codon positions and the nt substitutions were synonymous (i.e. do not alter the amino acid sequence). Seven (of the eight) nt substitutions were transitions $(\mathrm{C} \leftrightarrow \mathrm{T}$ or $\mathrm{A} \leftrightarrow \mathrm{G})$ and 1 was a transversion $(\mathrm{A} \leftrightarrow \mathrm{C})$ (Fig. 2).

\section{Interspecific variation}

DNA sequence analysis - T. melanosoma presented the exact same haplotype as the two $T$. infestans samples from the State of Paraná and was also very similar to the other $T$. infestans populations from Brazil (with the difference of only one silent substitution, Fig. 2). When compared to the more different Bolivian populations, it can be seen that the few (5-7) nucleotide (nt) substitutions occurred on the 3rd codon position and were silent substitutions, i.e. do not produce an amino acid change. On the other hand, the comparison of the T. melanosoma/T. infestans (PR) haplotype with T. brasiliensis revealed a significant degree of sequence divergence. There were $53 \mathrm{nt}$ substitutions (41on the 3rd position of the codon, 10 on the 1st, and 2 on the 2nd), and six of them were non-silent.

Cytogenetics - The chromosome complement of T. melanosoma is composed of 20 autosomes plus two sex chromosomes (XY for males and XX for females). Using the C-banding approach we observed that three autosomal pairs (and sometimes a fourth pair), show heterochromatic blocks in one or both chromosomal ends. The sex chromosomes exhibit an intermediate size. The Y chromosome is partially $\mathrm{C}$-heterochromatic while the $\mathrm{X}$ chromosome is euchromatic (C-negative).

In early meiotic prophase this species presents a large heterochromatic chromocenter formed by the association of C-heterochromatic blocks of the three large autosomal pairs and both sex chromosomes. The arrangement of the chromosomes during metaphase I and II and their segregation in both anaphases were as normally observed for other triatomine species.

In spite of the small number of individuals analyzed, we observed a great variability in the pat-

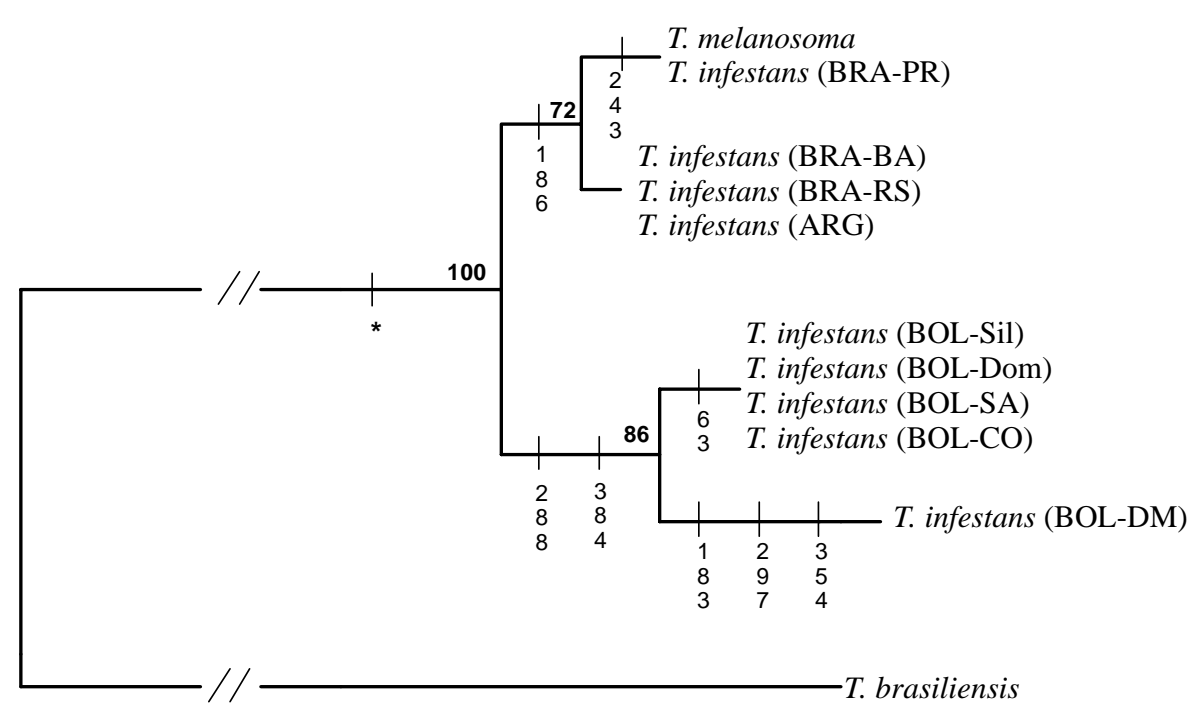

Fig. 3: deduced phylogenetic tree of nine Triatoma infestans populations, T. melanosoma and T. brasiliensis. Tree construction was based on DNA sequence data obtained from the mtCytb gene fragment of each species/population and analyzed by the Neighbor-Joining method. Bold numbers represent the bootstrap values supporting each clade. Vertical numbers are the shared derived characters (synapomorphies) that support each clade, or characterize each terminal lineage (autapomorphies). * Represents the fifty synapomorphies that support the T. infestans/T. melanosoma clade. 


\section{TABLE III}

Frequencies of C-band karyotypes observed in Triatoma melanosoma. The nomenclature is the same used by Panzera et al. (1992) for T. infestans: A morph, containing a $\mathrm{C}$-heterochromatic block in one chromosomal end, B morph, presenting Cheterochromatic blocks in both chromosomal ends and $\mathrm{C}$ morph, showing no C-band

\begin{tabular}{lc}
\hline C- KARYOTYPE & Number of individuals \\
\hline BB AA AA & 1 \\
BB BB AA & 4 \\
BB BC AA AC & 1 \\
BB BA AA AC & 1 \\
\hline
\end{tabular}

terns of C-bands (Table III). The amount of heterochromatin represents about $23-30 \%$ of the total autosomal length.

Comparison between T. melanosoma and $T$. infestans - No cytogenetic differences between $T$. infestans (Panzera etal. 1992) and T. melanosoma were detected (Fig. 4 a and b). Karyotype (number and size of chromosomes) as well as quantity, distribution, and meiotic behaviour of C-heterochromatin were similar to those observed in $T$. infestans individuals from natural populations of Uruguay (Panzera et al. 1992).

Cytogenetic analysis of the hybrids - The meiotic behavior in the hybrids is apparently normal. We observed a complete meiotic pairing between the autosomes of both species and no univalent was detected. The sex chromosomes also show a typical meiotic behavior. We did not observe any alteration in the morphology of the spermatid and spermatozoids.
Allozymes - Alleles found in the T. melanosoma sample were not different from those already known for T. infestans (Dujardin et al. 1998), except for the first locus of the IDH system (Idh1). By increasing the voltage from 100 to 110 , the existence of a previously undetected polymorphism was revealed. At this locus, a new, fast allele (Idh11) was fixed in the $T$. infestans population from Paraguay and in T. melanosoma, whereas the Bolivian (Andean), T. infestans population presented only the slow allele (Idh1-2, Table IV).

Morphometry - T. melanosoma showed differences with T. infestans of the same order than those found between conspecific, geographic populations of T. infestans (Fig. 5).

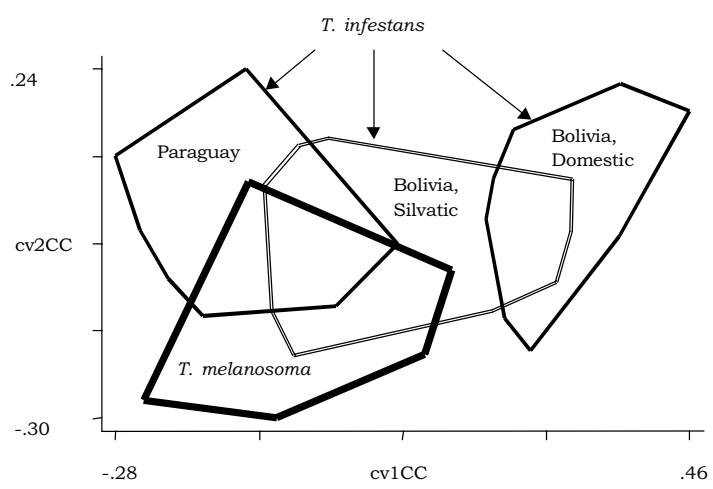

Fig. 5: factorial map constructed based on the measurements of the wings of adult Triatoma infestans and T. melanosoma insects. $\mathrm{Cv} 1 \mathrm{CC}$ and cv2 $\mathrm{CC}$ are first and second canonical variants or discriminant factors. Note that the level of differentiation between $T$. melanosoma and T. infestans is of the same order than between conspecific, geographic populations of $T$. infestans.

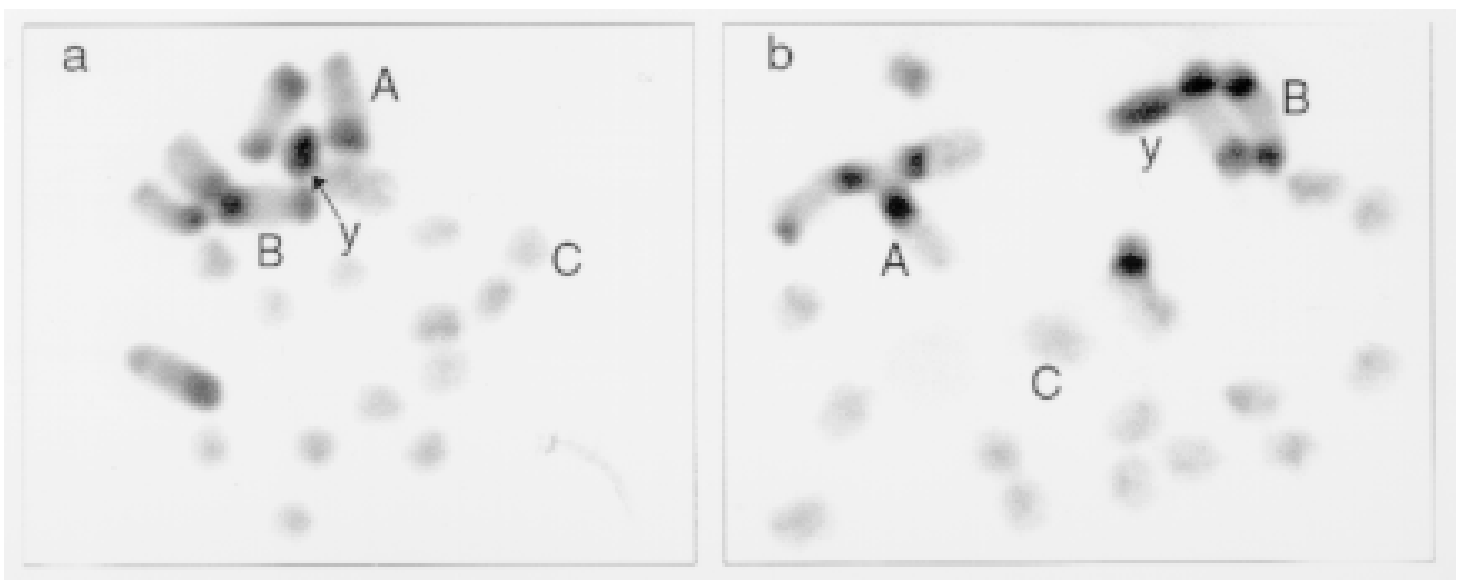

Fig. 4: C-banded spermatogonial prometaphases of Triatoma melanosoma (a) and T. infestans (b). Both species present 22 chromosomes (20 autosomes $+\mathrm{XY}$ ). Six autosomal pairs show C-blocks either in one (morph A) or in both chromosomal ends (morph B). The Y chromosome is completely heterochromatic. The rest of autosomes (morph C) and the $\mathrm{X}$ chromosome do not have any C-bands. Magnification: 2000X. 


\section{TABLE IV}

Polymorphic loci among two Triatoma infestans populations and T. melanosoma. Alleles were scored as present (1) or absent (0)

\begin{tabular}{lccc}
\hline & $\begin{array}{c}\text { T. infestans, } \\
\text { Bolivia } \\
\text { (Andes) }\end{array}$ & $\begin{array}{c}\text { T. infestans, } \\
\text { Paraguay }\end{array}$ & T. melanosoma \\
\hline Pgm-1 & 1 & 0 & 0 \\
Pgm-2 & 1 & 1 & 1 \\
Pgm-3 & 1 & 0 & 0 \\
6Pgdh-1 & 1 & 1 & 1 \\
6Pgdh-2 & 1 & 0 & 0 \\
Gpd-1 & 1 & 0 & 0 \\
Gpd-2 & 1 & 1 & 1 \\
Gpd-3 & 1 & 0 & 0 \\
Idh1-1 & 0 & 1 & 1 \\
Idh1-2 & 1 & 0 & 0 \\
\hline
\end{tabular}

Cross-mating experiments - The crossings in both directions were successful. F1 progeny insects with the $T$. infestans phenotype composed the great majority of $\mathrm{F} 1(98.5 \%)$. The percentage of hatched eggs was 53 for the 15 pairs between $T$. melanosoma males and T. infestans females. The 12 pairs of the other combination yield a lower percentage $(44,6 \%)$ of hatching.

\section{DISCUSSION}

Our results show that the silvatic and domestic T. infestans from Jamach'Uma, Bolivia, share the same haplotype, therefore giving support to similar observations based on allozyme (Dujardin et al. 1987) and cytogenetic markers (F Panzera, pers. comm.). It has been suggested that silvatic and domestic T. infestans populations may be undergoing a process of isolation. The fact that these two populations presented not only the same gene frequencies at two polymorphic loci but were also infected by the same strain of $T$. cruzi, prompted the idea that the silvatic populations could be, in fact, feral derivatives of the domestic colonies (Dujardin et al. 1987, 1998). On the other hand, metric and genetic (based on RAPD profiles) differences between the same silvatic and domestic T. infestans populations have been interpreted as indication of their incipient separation not detected by the allozyme analysis (Dujardin et al. 1997). Nevertheless, the fact that morphomeric differences were also detected among geographically close domestic $T$. infestans populations from Uruguay, raises the question of whether these differences are genetically determined (and may therefore be interpreted under an evolutionary view) or if they are a consequence of the sampling of (recent) isolated founder populations.
The current hypothesis put forward to explain the distribution of T. infestans in South America states that the domestication of wild guinea-pigs (the host of sylvatic T. infestans) in Bolivia was the first step in the T. infestans trend towards domesticity. Since by using sequence analysis we were able to detect a substructuring in the domestic populations sampled (see below) it seems unlikely that an earlier historical event (the transition from the silvatic to the domestic habitat) was not revealed by the data. It is possible, however, that true silvatic (instead of feral) populations are still to be found.

Each individual T. infestans population analyzed presented a single haplotype. No within population variation was detected. This lack of polymorphism precluded the estimation of levels of gene flow among populations. However, since four distinct geographical haplotypes were observed, the populations were treated as different evolutionary lineages and submitted to a phylogenetic analysis. The first species chosen as the outgroup was T. melanosoma, because of its affinity with the ingroup (the $T$. infestans populations). However, T. melanosoma turned out to be genetically so similar to some $T$. infestans samples that another related species (T. brasiliensis) was included in the analysis to root the generated tree.

The phylogenetic analysis of the $T$. infestans populations reveals three major splitting events. The first event is the separation of the hypothetical ancestral form of the populations from Bolivia from the hypothetical ancestral form of the populations from Argentina and Brazil. The next two events are the separation of the Bolivian haplotypes into the Andean haplotypes (CO, SA, Sil, Dom) and Chaco haplotype (DM); and the separation of the Argentina/Brazil samples into a more common haplotype (presented by ARG, RS, BA) from the PR haplotype (and T. melanosoma, see below) (Fig. 3 ). It has been suggested, based on arqueological findings and historical reconstructions, that $T$. infestans originated in Bolivia, and was originally introduced into human dwellings about 4500 years ago, with the domestication of wild guinea-pigs. From this center of origin, the species was dispersed throughout Latin America, in association with human migrations. According to this hypothesis, $T$. infestans would have invaded southern Brazil coming across Argentina and Paraguay to be later introduced into the northeast parts of this country. Our data is in partial agreement with this hypothesis as it supports the invasion of Brazil, but only from insects coming from Argentina (and not from Paraguay). The reason for this is that the $T$. infestans DM haplotype (that is very distinct from the two haplotypes from Brazil) comes from a re- 
gion right in the (imaginary) human migration pathway from Bolivia to Brazil (through Paraguay). However, this observation needs to be confirmed by the analysis of domestic insects from both the Bolivian Chaco and Paraguay.

The differentiation between $T$. infestans from Bolivia and Argentina/Brazil (or Andean/nonAndean) reported here has also been detected by cytogenetic methods (F Panzera, manuscript in preparation), and agrees with morphological differences observed in the male genitalia of insects from Bahia, Brazil and Cochabamba, Bolivia (Pires et al. 1998). Although the efficiency of allozyme markers in detecting such geographical structuring is controversial (Garcia et al. 1995, Dujardin et al. 1998), our present results appear to support it (Table IV). The finding of a "hidden" diagnostic polymorphism in the Idh1 locus accords well with this scenario and also points out the high similarity between T. melanosoma and T. infestans.

T. melanosoma is an entirely black triatomine first recognized in 1984 from Missiones, Northeast Argentina. It is morphologically very similar to $T$. infestans and was until 1994 considered to be a subspecies of the latter (Martinez et al. 1987). It was raised to the specific level based on crossmating experiments indicating partial sterility and on the fact that dark coloration was shown to be a stable character over multiple generations (Lent et al. 1994).

Our DNA sequence comparison shows that $T$. melanosoma is identical to the T. infestans samples from Paraná (PR) and very similar to the other samples from Brazil and Argentina (Figs 2, 3). It is interesting to note that Missiones, Argentina, (the collection site of T. melanosoma) is geographically close to the State of Paraná, Brazil (Fig. 1).

There is no direct estimation of what percentage of DNA sequence divergence a taxon should present to be considered a good species. Clearly, it is hard to believe that it would display total identity to another species as reported here, unless introgression occurred recently in the history of the two species (as suggested by Garcia and Powell, for T. infestans and T. platensis). Introgression appears not to be the case here, because this phenomenon generally occurs with mtDNA markers, making it difficult to explain the identity based on nuclear markers presented here (see below). The high levels of sequence divergence (13\%, $53 \mathrm{bp}$ differences) presented by $T$. brasiliensis (when compared to T. infestans and T. melanosoma) reveal that even though it belongs to the " $T$. infestans complex", it is not very closelly related to $T$. infestans. Probably, the best candidates to provide good parameters to reveal the degree of divergence one should expect to find when dealing with spe- cies closely related to $T$. infestans would be $T$. platensis or T. delpontei (Panzera et al. 1995, Pereira et al. 1996). Nevertheless, the comparison of T. sordida and T. garciabesi may shed some light on this subject. Since T. garciabesi was until recently (Jurberg et al. 1998) thought to be a geographical variant of $T$. sordida, these species can be considered good representatives of closely related species in the "T. infestans complex". These two species present $8 \%$ of sequence divergence (31 bp differences, Monteiro et al. unpublished results), revealing that even closely related species present a considerable amount of nt differences.

Cytogenetic studies in the triatomines are based mainly on the description of the number and size of chromosomes. At present, the chromosome number of 49 triatomine species is known (Panzera et al. 1998). The most frequent diploid chromosome number in the genus Triatoma is 22 , with an $\mathrm{XX} / \mathrm{XY}$ system, the same as observed in $T$. melanosoma (Fig. 4a). Despite the homogeneity in the chromosome number, there are several characters that differentiate triatomine species, such as number, localisation and size of heterochromatic regions (C-bands) as well as chromosome behavior during the male meiotic prophase. T. infestans and T. melanosoma present the same distribution and quantity of C-bands (Figs $4 \mathrm{~b}$ and $4 \mathrm{a}$, respectively).

Chromosome meiotic behavior is species specific and has been particularly useful to differentiate closely related species (Panzera et al. 1995, 1997). For example, T. platensis, a species closely related to T. infestans, presents a distribution of the C-bands similar to that of $T$. infestans and $T$. melanosoma, but it has a different chromocenter during the meiotic prophase. The chromocenter of T. platensis is formed by a variable number of autosomes (Panzera et al. 1995), while that in $T$. infestans and T. melanosoma is always comprised of three autosomal bivalents. Currently, $T$. melanosoma is the only species that presents autosomal C-heterochromatic regions cytogenetically identical to any other species (T. infestans).

A good indication of cytological similarities between species comes from the meiotic analysis of interspecific hybrids. Meiotic behavior and particularly chromosome pairing depend on the similarity between the sets of homologous chromosomes from the parental species. For this reason, the degree of asynapsis in the meiosis of interspecific hybrids allows the evaluation of the taxonomic distances between the parental species. In the meiosis of the hybrids between $T$. infestans and $T$. rubrovaria, two species that are not closely related, the chromosomes of the parental species do not pair completely and several univalents are ob- 
served, producing a decrease in the fertility of the hybrids (Usinger et al. 1966). The same was observed in the hybrids between $T$. infestans and $T$. pseudomaculata (Schreiber et al. 1974). On the other hand, in the hybrids between T. infestans and T. platensis, two closely related species, the meiotic behaviour and paring are normal and the fertility is not reduced (Scvortzoff et al. 1995). The normal behavior of the chromosomes of the hybrids between $T$. infestans and T. melanosoma points out to the large genetic similarities between their sets of chromosomes.

The reciprocal crosses show that the two species are inter-fertile in both directions, contrasting to MA Lopez personal observation (in Lent et al. 1994). In fact, the crosses that Lopez found to be more difficult (male T. melanosoma with female T. infestans) were the ones that gave a higher (53\%) percentage of hatching in our experiments. One weakness of our study is the fact that it lacks control crossings (crosses within each species), making it difficult to detect slight decreases in fertility. Also, comparisons with other studies should be done with caution, since the experimental conditions may vary between different laboratories. For example, it has been shown that the manipulation of $T$. infestans colonies causes a severe reduction in the number of fertile eggs layed by the females (Tolezano et al. 1984). The fact that our colonies were subjected to daily manipulation may account for the lower levels of hatching that we observed between species if compared to other (within) $T$. infestans crossings (88\%, PerlowagoraSzumlewics 1969), since some of our crossings produced a high percentage of offspring.

Triatomine species are currently defined according to the biological species concept (Usinger et al. 1966) and identified based on external morphology and chromatic characters (Lent \& Wygodzinsky 1979). However, discrepancies may arise in the case of sibling (Lent et al. 1993, Panzera et al. 1997, Noireau et al. 1998), or polytypic species (Monteiro et al. 1998, Jurberg et al. 1998). Recently, information coming from the employment of molecular tools is increasing our knowledge of the specific status in the Triatominae.

If the morphological (chromatic) differences detected in T. melanosoma had been confirmed at the morphometric, chromosomal or molecular levels, or if the cross-mating experiments revealed the existence of any kind of pre or post zygotic barrier, then, its status as a separated species would have been confirmed. This study did not detect any such differences between these two species, and although this result does not invalidate the taxonomic status of T. melanosoma, it suggest that this species could represent no more than an inbred founder population of $T$. infestans where a putative melanic (recessive) allele became fixed.

\section{ACKNOWLEDGEMENTS}

To Brian Holloway and the staff of the NCID Biotechnology Core Facility for synthesis of the oligonucleotide primers, Vanda Cunha for assistance in the crossmating experiments and Antonieta $\mathrm{R}$ Arias for field colection of insects from Paraguay. This paper is part of the Ph.D. thesis of Fernando A Monteiro at the Departamento de Genética da Universidade Federal do Rio de Janeiro. Some of the specimens used in this study came from the International Triatomine Taxonomy Reference Laboratory, Fiocruz.

\section{REFERENCES}

Beard CB, Mills Hamm D, Collins FH 1993. The mitochondrial genome of the mosquito Anopheles gambiae: DNA sequence, genome organization, and comparisons with mitochondrial sequences of other insects. Insect Mol Biol 2: 103-124.

Casini CE, Dujardin JP, Martínez M, Bentos-Pereira A, Salvatella R 1995. Morphometric differention between two geographic populations of Tratoma infestans in Uruguay. Res Rew Parasitol 55: 25-30.

Dujardin JP, Bermudez H, Casini C, Schofield CJ, Tibayrenc M 1997. Metric differences between silvatic and domestic Triatoma infestans (Hemiptera, Reduviidae) in Bolivia. J Med Entomol 34: 544-552.

Dujardin JP, Schofield CJ, Tibayrenc M 1998. Population structure of Andean Triatoma infestans: allozyme frequencies and their epidemiological relevance. Med Vet Entomol 12: 20-29.

Dujardin JP, Tibayrenc M, Venegas E, Maldonado L, Desjeux P, Ayala FJ 1987. Isoenzyme evidence of lack of speciation between wild and domestic Triatoma infestans (Heteroptera: Reduviidae) in Bolivia. J Med Entomol 24: 40-45.

Efron B 1982. The Jackknife, the Bootstrap and Other Resampling Plans, CBMS-NSF Regional Conference Series in Applied Mathematics, Monograph 38, SIAM, Philadelphia.

Garcia BA, Powell JR 1998. Phylogeny of species of Triatoma (Hemiptera: Reduviidae) based on mitochondrial DNA sequences. J Med Entomol 35: 232238.

Hennig W 1966. Phlogenetic Systematics, University of Illinois Press, Urbana.

Jurberg J, Galvão C, Lent H, Monteiro FA, Lopes C M, Panzera F, Perez R 1998. Revalidação de Triatoma garciabesi Carcavallo, Martinez, Cichero, Prosen \& Ronderos, 1967 (Hemiptera-Reduviidae). Entomologia y Vectores 5: 107-122.

Kumar S, Tamura K, Nei M 1993. MEGA: molecular evolutionary genetics analysis, Version 1.0. Institute of Molecular Evolutionary Genetics, The Pennsylvania State University, University Park.

Lent H, Jurberg J 1985. Sobre a variação intra-específica em Triatoma dimidiata (Latreille) e Triatoma infestans (Klug) (Hemiptera: Reduviidae). Mem Inst Oswaldo Cruz 80: 285-299.

Lent H, Wygodzinsky P 1979. Revision of the 
Triatominae (Hemiptera: Reduviidae) and their significance as vectors of Chagas disease. Bull Am Mus Nat His 163: 123-520.

Lent H, Jurberg J, Galvão C, Carcavallo RU 1994. Triatoma melanosoma, novo status para Triatoma infestans melanosoma Martinez, Olmedo \& Carcavallo, 1987 (Hemiptera: Reduviidae). Mem Inst Oswaldo Cruz 89: 353-358.

Lyman DF, Monteiro FA, Escalante AA, CordonRosales C, Wesson DM, Dujardin JP, Beard CB 1999. Mitochondrial DNA sequence variation among triatomine vectors of Chagas disease. Am J Trop Med Hyg 60: 377-386.

Monteiro FA, Costa J, Sole-Cava AM 1998. Genetic confirmation of the specific status of Triatoma petrochii (Hemiptera: Rediviidae: Triatominae). Ann Trop Med Parasitol 92: 897-900.

Noireau F, Flores R, Gutierrez T, Dujardin JP 1997. Detection of sylvatic dark morphs of Triatoma infestans in the Bolivian Chaco. Mem Inst Oswaldo Cruz 92: 583-584.

Noireau F, Gutierrez T, Zegarra M, Flores R, Breniere F, Cardozo L, Dujardin JP 1998. Crypic speciation in Triatoma sordida (Hemiptera: Reduviidae) from the Bolivian Chaco. Trop Med Int Heath 3: 364-372.

Panzera F, Alvarez F, Sanchez-Rufas J, Pérez R, Suja J, Scvortzoff E, Estramil E, Dujardin JP, Salvatella R 1992. C-heterochromatin polymorphism in holocentric chromosomes of Triatoma infestans (Hemiptera-Reduviidae). Genome 35: 1068-1074.

Panzera F, Hornos S, Pereira J, Cestau R, Canale D, Diotaiuti L, Dujardin JP, Pérez R. 1997. Genetic variability and geographic differentiation among three species of triatomine bugs (Hemiptera: Reduviidae). Am J Trop Med Hyg 57: 732-739.

Panzera F, Pérez R, Panzera Y, Alvarez F, Scvortzoff E, Salvatella R 1995. Karyotype evolution in holocentric chromosomes of three related species of triatomines (Hemiptera: Reduviidae). Chromosome Research 3: 143-150.

Panzera F, Scvortzoff E, Pérez R, Panzera Y, Hornos S, Cestau R, Nicolini P, Delgado V, Alvarez F, Mazzella M, Cossio G, Martínez M, Salvatella R 1998. Citogenetics of triatomines, p. 621-664. In R Carcavallo, Atlas de Triatominos de América, Fundação Oswaldo Cruz, Rio de Janeiro.

Pereira J, Dujardin JP, Salvatella R, Tibayrenc M 1996.
Enzymatic variability and phylogenetic relatedness among Triatoma infestans, T. platensis, T. delpontei and T. rubrovaria. Heredity 77: 47-54.

Perez R, Panzera Y, Scafiezzo S, Mazzella M, Panzera P, Dujardin JP, Scvortzoff E 1992. Cytogenetics as a tool for triatominae species distinction. Mem Inst Oswaldo Cruz 87: 353-361.

Perlowagora-Szumlewicz A 1969. Estudos sôbre a biologia do Triatoma infestans, o principal vetor da doença de Chagas no Brasil. (Importância de algumas de suas características biológicas no planejamento de esquemas de combate a esse vetor). Rev Bras Malariol D Trop 21: 117-159.

Pires HHR, Barbosa SE, Margonari C, Jurberg J, Diotaiuti L 1998. Variations of the external male genitalia in tree populations of Triatoma infestans Klug, 1834. Mem Inst Oswaldo Cruz 93: 479-483.

Schofield CJ 1988. Biosystematics of the Tratominae, p. 285-312. In MW Service, Biosystematics of Haematophagous Insects, Clarendon Press, Oxford.

Schofield CJ 1992. Eradication of Triatoma infestans: a new regional programme for southern Latin America. Am Soc Belg Med Ttrop 72: 69-70.

Schreiber G, Coelho de Pinto A, Parentoni R, De Abreu A, Salgado T, Leite de Godoy JR 1974. Cytogenetics of Triatominae: II. Spermatogenesis in hybrids between Triatoma infestans and Triatoma pseudomaculata (Hemiptera-Reduviidae). Rev Bras Genet 34: 1-10.

Scvortzoff E, Martinez M, Beltrame B 1995. Análisis citogenético de algunos híbridos de Triatoma Laporte 1832 (Hemiptera-Reduviidae). Bol Soc Zool Uruguay 9: 79-90.

Tamura K, Nei M 1993. Estimation of the number of substitutions in the control region of mitochondrial DNA in humans and chimpanzees. Mol Biol Evol 10: $512-526$.

Tolezano JE, Araújo MFL, Chieffi PP, Valentim AM, Ribeiro SS 1984. Variáveis relacionadas ao desenvolvimento de Triatoma infestans Klug, 1834 em condições de laboratório. Efeitos da manipulação na sobrevivência e na fertilidade. Rev Inst Adolfo Lutz, 44: 81-86.

Usinger RL, Wygodzinsky P, Ryckman R. 1966. The biosystematics of Triatominae. Ann Rev Entomol 11: 309-330. 